COMMENT. A longitudinal clinical and electophysiologic study of Charcot-Marie-Tooth disease type 1A with $17 \mathrm{p}$ duplication in infancy and early childhood is described from the University Hospital "Marques de Valdecilla," Santander, Spain (Garcia A, Combarros O, Calleja J, Berciano J. Neurology April 1998;50:1061-1067). Twenty at-risk children from 6 unrelated CMT-1A families were examined in the first 5 years of life, and 12 were affected. Initially 2 had symptoms, and 5 were symptomatic at the last exam. MCV and SCV were abnormal in $50 \%$ at the beginning and in $83 \%$ at conclusion of study. After 2 years of age, all affected children had abnormal MCV, SVC, and F-waves. Serial electophysiologic studies can detect the CMT-1A gene carrier in infancy.

\title{
CLINICAL AND GENETIC DIAGNOSIS OF FRIEDREICH'S ATAXIA
}

The clinical diagnostic criteria and genetic testing for Friedreich's ataxia are reviewed from the National Hospital for Neurology and Neurosurgery, Queen Square, London, UK. The essential clinical diagnostic criteria, after Harding, are onset before 25 years, progressive ataxia, absent tendon reflexes, axonopathy, and dysarthria. Additional criteria include scoliosis, cardiomyopathy, optic atrophy, pes cavus, and diabetes. The gene for Friedreich's ataxia is mapped to chromosome 9 q13, with an X25 transcript and GAA mutation repeat in intron 1 of the frataxin gene. The repeat length is correlated with the age at onset and the presence of cardiomyopathy. The frataxin protein may be an iron transporter within the mitochondria. (Wood NW. Diagnosing Friedreich's ataxia. Arch Dis Child March 1998;78:204-207). (Respond: Dr Nicholas W Wood, Institute of Neurology, Queen Square, London WC1N 3BG, UK).

COMMENT. A direct genetic test permits diagnosis of Friedreich's ataxia in forme fruste cases, including those with retained reflexes or onset later than 25 years. The author postulates that the clinical manifestations of Friedreich's ataxia coupled with the nature of the frataxin protein have the hallmarks of a mitochondrial disease.

\section{INFECTIOUS DISORDERS}

\section{ACUTE HEMIPLEGIA WITH CHICKENPOX}

A case of an 18-month-old girl who developed a right hemiplegia 10 days after onset of varicella infection is reported from the Division of Pediatric Neurology, Istanbul University, Turkey. The child was admitted with hemiparesis following a focal clonic seizure involving the arm and leg. She was afebrile and had healed varicella lesions on the trunk. CT and MRI showed infarction of the left putamen and internal capsule. MR angiography was normal. A mild hemiparesis had persisted at 7-month follow-up. (Yilmaz K, Caliskan M, Akdeniz C et al. Acute childhood hemiplegia associated with chickenpox. Pediatr Neurol April 1998;18:256-261). (Respond: Dr Yilmaz, Bulbuldere Cad, No 5/2 Uskudar, 81130 Istanbul, Turkey).

COMMENT. The authors' review of the literature cites 21 previous reports of hemiparesis and infarct following varicella in children. The interval between the rash and hemiparesis was 10 days to 4 months (mean 9 weeks). EEGs showed focal abnormalities in one half the cases. Angiography had revealed arterial stenoses involving the middle cerebral. Occasional cases of hemiparesis presented before the rash appeared. Pre-eruptive varicella encephalitis with cerebellar ataxia is also reported in a child treated at the Mayo Clinic (Goldston EC, Millichap JG, 
Miller RH. Am J Dis Child 1963;106:197).

\section{CEREBELLITIS AND ACUTE HYDROCEPHALUS}

A case of obstructive hydrocephalus and bilateral cerebellitis with swelling in a 14-year-old boy is reported from the Department of Child Health, St George's Hospital, and the Departments of Neurosurgery and Neuroradiology, Atkinson Morley's Hospital, London, UK. The child presented with a 2-month history of recurrent headache and a 2-week history of occipital headache, nausea and vomiting, without signs of acute infection or immunization. Fundi showed bilateral papilledema. Apart from mild dysdiadochokinesia, the neurologic exam was otherwise normal. MRI showed obstructive hydrocephalus and marked bilateral cerebellar swelling with increased signal on T-2 weighted imaging, compatible with acute inflammation. Clinical and MRI signs resolved in 4 weeks following treatment with corticosteroids, and the neurologic exam was normal at 12 month follow-up. (Aylett SE, O'Neill KS, De Sousa C, Britton J. Cerebellitis presenting as acute hydrocephalus. Child's Nerv Syst March 1998;14:139-141). (Respond: Dr SE Aylett, The Wolfson Centre, Mecklenburgh Square, London WC1N 2AP, UK).

COMMENT. The clinical and MRI findings and recovery following steroids were considered consistent with a parainflammatory cerebellitis, although viral studies were negative. Prompt diagnosis and therapy are important because of the danger of tonsillar herniation.

\section{ATTENTION DEFICIT DISORDERS}

\section{CEREBELLAR VERMIS ANOMALY IN ADHD}

Cerebellar and vermal volumes were measured by quantitative MRI studies in 46 right-handed boys with attention deficit hyperactivity disorder (ADHD) and 47 matched healthy controls, and results were analyzed at the Child Psychiatry Branch, National Institute of Mental Health, Bethesda, MD. Both area and volumetric analyses showed a smaller cerebellar vermis in boys with ADHD, and the posterior inferior lobules VIII to X were particularly involved. Total cerebral volume was $6 \%$ smaller in the ADHD group, also. WISC-R vocabulary and block design scores were significantly lower in ADHD compared to control children. The findings were not related to prenatal alcohol exposure nor to methylphenidate treatment. A cerebello-thalamo-prefrontal circuit dysfunction is postulated in ADHD. (Berquin PC, Giedd JN, Jacobsen LK et al. Cerebellum in attention-deficit hyperactivity disorder. A morphometric MRI study. Neurology April 1998;50:10871093). (Reprints: Dr FX Castellanos, 10 Center Drive, Room 3N202, Bethesda, MD 20892).

COMMENT. The cerebellar vermis is smaller in right-handed boys with $\mathrm{ADHD}$, and the reduction in volume involves particularly the posterior inferior lobules VIII to $\mathrm{X}$. The smaller cerebral volumes might explain the significantly lower IQ scores in ADHD children compared to controls. Previous studies by Dr Castellanos at the NIH showed that ADHD was associated with loss of normal asymmetry in the caudate nucleus, smaller right anterior frontal area, and smaller cerebellum, and IQ scores correlated with total cerebral volume. Researchers at the Masssachusetts General Hospital, Boston, have reported a smaller splenium of the corpus callosum in ADHD children, and the Johns Hopkins group of investigators found a smaller globus pallidus volume (see Progress in Pediatric Neurology III, 1997;p 212). These studies add to the growing volume of data supporting a structural brain pathology as the basis for ADHD (Millichap JG. 